P-398 CHEMICAL RISK ASSESSMENT FOR SMALL BUSINESS: DEVELOPMENT OF A TOOL AND RESOURCES

${ }^{1}$ Thomas Tenkate, Desre Kramer, Daniel Drolet, Peter Strahlendorf, Olga-Sana Candeloro, Cheryl Peters, D Linn Holness. ${ }^{1}$ Ryerson University, Canada

\subsection{6/OEM-2021-EPI.312}

Introduction Small to medium sized enterprises (SMEs) employ the majority of Canadians, but find it difficult to assess the risks of the chemicals they use and to implement effective control and prevention measures. As such, there is an ongoing need to provide SMEs with easy-to-use tools to identify chemical hazards and assess the risks posed by exposure to chemical agents.

Objective To develop CHAP-Risk, a software tool to assist SMEs to easily undertake health and safety risk assessments of the chemicals/hazardous products they use, and assist them to implement effective control measures.

Methods We have employed a 'User Centered Design' approach which allows end-users to influence how the design takes shape. Our eight step development process is: (1) establish a project reference group, (2a) develop a trial version of CHAP-Risk and its training program based on an extensive review of existing tools and resources, (2b) recruit trial workplaces -6 workplaces in Ontario were recruited to trial the tool, (3) pre-trail evaluation, (4) training, (5) workplace trial, (6) post-trial evaluation, (7) develop final versions of CHAP-Risk and the training, and (8) CHAP-risk and resources available on website for free download (by September 2021).

Results The draft version of CHAP-Risk is currently being trialed by workplaces (trial to be completed in June/July 2021). Initial feedback is positive in regard to the potential benefits and application of the tool, particularly related to improving the 'workplace contextualization' of the WHMIS 2015 requirements. However, a number of technical improvements are currently needed to enhance the user experience.

Conclusion Tools to support SMEs in undertaking chemical risk assessments are important and the current trial of CHAPRisk indicates that it will provide SMEs with a useful tool to assist them in assessing and more safely managing their workplace chemicals.

\section{P-400 TELEWORKERS' FLOURISHING DURING COVID-19 LOCKDOWN: THE WORK-FAMILY RELATIONSHIP}

${ }^{1}$ Vânia Carvalho, Rita Rita, Maria José Chambel. 'Universidade de Lisboa, Portugal

10.1136/OEM-2021-EPI.313

Introduction Although research on work-family relationship have shown the relevance of balance between these two life domains to explain well-being, the analysis of this effect during COVID-19 lockdown has not yet been examined.

Objectives In this study based on the work-family boundary theory management, we considered that the segmentation from work-to-family had a positive relationship with workfamily balanced, which in turn had a positive relationship with flourishing.

Method A sample of 108 teleworkers during the first COVID-19 lockdown (March-April 2020) in Portugal without previous experience with telework answered an on-line questionnaire.
Results The results analyzed with PROCESS (model 4) allowed us to observe that work-to-family segmentation was related with work-family balance and that this work-family balance was the mechanism that explained the positive relationship between work-to-family segmentation and flourishing.

Conclusion Telework is a situation that makes it difficult to establish boundaries between work and family. There must be tools that invest in the development of skills of teleworkers to segment work and family, in order to promote a balance between these domains and, consequently promote teleworkers' well-being.

\section{P-407 WORK-RELATED CARPAL TUNNEL SYNDROME AND IMPACT ON MEDICAL FITNESS FOR WORK}

Saloua Ismail, 'Siwar Chemingui, Jihen Hsinet, Amani Dallagi, Nihel Khouja, Ines Aissa, Aida Benzarti, Abdelmajid Ben Jemaa. 'Hôpital La Rabta, Tunisia

\subsection{6/OEM-2021-EPI.314}

Introduction Carpal tunnel syndrome (CTS) is the most common occupational disease in Tunisia. It has various professional and extra-professional risk factors.

Objectives Describe the socio-professional, clinical and paraclinical characteristics of work-related CTS and specify its impact on medical fitness for work.

Methods Descriptive retrospective study on cases of CTS collected in the occupational medicine and diseases department of the Rabta Hospital in Tunis, between 2001 and 2017.

Results We identified 66 cases with a clear predominance of women (94\%) and a mean age of $43 \pm 7$ years. The sectors of activity that provided the most CTS were the textile industry $(30 \%)$, the wiring sector $(14 \%)$ and the food industry (12\%). The most represented job was unskilled worker (82\%). The predominant occupational risk factors were extreme wrist postures (89\%), fine and precise movements (61\%) and repetitive movements (46\%). The time to onset of symptoms was $15 \pm 8$ years after employment. The most frequent symptoms were paresthesia in the median nerve territory (90\%), wrist pain $(26 \%)$ and muscle weakness $(18 \%)$. The CTS was most often bilateral (59\%), of the sensory-motor type (23\%) and severe (33\%), justifying a transfer to another workstation $(55 \%)$, a workstation adaptation $(29 \%)$ or a temporary $(4 \%)$ or permanent $(6 \%)$ inability to work. From a medico-legal standpoint, this pathology was considered, in $79 \%$ of cases, as an occupational disease compensable under the table relating to gestures and postures.

Conclusion CTS is a multifactorial musculoskeletal disorder involving significant professional repercussions, hence the need to put in place a structured prevention plan in the most affected sectors.

\section{P-409 MEDICAL FITNESS TO WORK FOLLOWING ACUTE CORONARY SYNDROME}

'Ines Aissa, Saloua Ismail, Nihel Khouja, Siwar Chemingui, Jihen Hsinet, Amani Dallagi, Aida Benzarti, Abdelmajid Ben Jemaa. 'Faculty of Medicine of Tunis, Tunisia

\subsection{6/OEM-2021-EPI.315}

Introduction Acute coronary syndrome (ACS) may, due to myocardial ischemia, limit a person's physical abilities and affect his medical fitness to work. 
Objectives Describe the socio-professional, clinical and paraclinical characteristics of ACS and their impact on medical fitness to work.

Methods Descriptive retrospective study of cases of patients with history of an ACS, who have consulted the department of occupational medicine in Rabta Hospital, between 2002 and 2020, to evaluate their medical fitness to work.

Results Our series included 43 patients with a male predominance $(81 \%)$ and a mean age of $52.1 \pm 7.2$ years. The main sectors concerned were transport (21\%), construction (19\%) and health (17\%). Patients were mainly employed as unskilled workers (44\%) and professional drivers (28\%). Sixty two per cent of the employees were in a security position, 55\% were exposed to severe weather, and $40 \%$ had a work requiring significant muscular effort. ACS was due to an ST-segment elevation myocardial infarction in 64\% of cases. Coronography showed tight stenosis of the left anterior descending artery (76\%), the right coronary artery $(50 \%)$, and the left circumflex artery (44\%). Coronary angioplasty was indicated in $85 \%$ of cases and coronary artery bypass surgery in $15 \%$ of cases. The mean left ventricular ejection fraction was $54 \%$ and was higher than $60 \%$ in $42 \%$ of cases. Workstation adjustment was proposed in $26 \%$ of patients, while $26 \%$ were transferred to another workstation. Permanent Disability was reported for $20 \%$ of patients, $14 \%$ had a temporary inability to work, $11 \%$ were kept fit to work without restriction and $3 \%$ had received early retirement.

Conclusion The management of ACS should be multidisciplinary, involving the attending and the occupational physician, including an appropriate cardiac rehabilitation programme, in order to facilitate the socio-professional reintegration of the patient.

\section{P-410 PROFILE OF OCCUPATIONAL PNEUMOCONIOSIS IN TUNISIA: ABOUT 14 CASES.}

${ }^{1}$ Amani Dallagi, Nihel Khouja, Jihen Hsinet, Ines Aissa, Saloua Ismail, Siwar Chemingui, Aida Benzarti, Abdelmajid Ben Jemaa. ${ }^{1}$ Faculté de médecine de Tunis, Tunisia

\subsection{6/OEM-2021-EPI.316}

Introduction Pneumoconiosis are interstitial pulmonary pathology induced by prolonged inhalation of inorganic particles, especially encountered in the workplace. Despite their decline in recent years, they have continued to pose an occupational health problem in Tunisia.

Objective To study the socio-professional, clinical and medicolegal characteristics of pneumoconiosis and to assess their impact on ability to work.

Methods Retrospective descriptive study of pneumoconiosis cases referred for professional etiological investigation to the Department of Occupational Medicine of the Rabta Hospital, in Tunis.

Results These were 14 predominantly male patients, with a mean age of $56.57 \pm 12.32$ years and an average professional length of $23 \pm 9.44$ years. They mainly worked in the underground works sector (4 cases), the building materials industry (3 cases) and metallurgy ( 2 cases). They were exposed to free silica mineral dust (11 cases), iron oxide fumes (3 cases) and asbestos dust (2 cases), in the absence of appropriate personal protective equipment for all patients. The time to onset of symptoms from onset of exposure was $27.36 \pm 12.7$ years. They mainly reported exertional dyspnea (14 cases), cough (8 cases) and chest pain (5 cases). Clinically, crackling was objectified in 9 patients and digital clubbing in 3 patients. Paraclinically, radiological signs of pulmonary fibrosis were objectified in 12 cases and emphysema in 4 cases, a restrictive ventilatory disorder was found in 4 cases. Bronchoalveolar lavage was performed in 6 patients and returned pathologically in three cases. Pulmonary disease was at the stage of chronic respiratory failure in one case. Despite the occupational exposure, only 10 cases were declared as compensable occupational diseases: 7 cases of silicosis, 2 cases of asbestosis and 1 case of siderosis. This morbidity justified a workstation layout for 4 patients and permanent incapacity for 2 others.

Conclusion Given the severity of pneumoconiosis and lack of curative treatment, prevention seems essential.

\section{P-413 WORK-RELATED STRESS IN THE OPERATING ROOM: A CROSS SECTIONAL STUDY IN DIFFERENT HEALTH STRUCTURES IN TUNIS}

Nihel Khouja, 'Ines Aissa, Saloua Ismail, Siwar Chemingui, Jihen Hsinet, Amani Dallagi, Aida Benzarti, Abdelmajid Ben Jemaa. ${ }^{1}$ Faculty of Medicine of Tunis, Tunisia

\subsection{6/OEM-2021-EPI.317}

Introduction Working in the operating room exposes to multiple psycho-organizational constraints that can cause negative repercussions on the health of the workers and on their performance at work.

Objectives To study psychosocial and organizational risk factors to which paramedical staffs in operating theatres are exposed, and to assess the level of stress at work and its impact on their health and on their performance at work.

Methods A descriptive cross-sectional study involving paramedical staff in operating rooms working in different health structures in Tunis, and based on a survey including the Karasek and Siegrist models.

Results The study included 91 paramedical staff with a mean age of $30.71 \pm 7.9$ years and a mean professional length of service of $4.80 \pm 5.55$ years. They worked $7 \pm 2.2$ hours/day on a fixed morning schedule $54.9 \%$ of the time and night shifts $23.1 \%$ of the time. They reported 4.5 \pm 1.67 surgical procedures/day. They were dissatisfied with the general conditions of their work in $83.6 \%$ of cases and $60.5 \%$ of them reported being victim of violence. They reported stress-related symptoms such as fatigue (57.8\%), headache $(56.7 \%)$, muscular pain $(53.3 \%)$, anxiety $(45.6 \%)$, mood disorders $(42.2 \%)$, memory $(45.6 \%)$ and concentration disorders (37.8\%). Repercussions on work were repeated delays $(34.4 \%)$, absenteeism $(30 \%)$ and the occurrence of errors $(9.8 \%)$. The assessment of the stress at work showed high psychological demands in $81.3 \%$ of cases and low levels of decision latitude in $49.5 \%$ of cases. $40.7 \%$ was exposed to Efforts-Rewards imbalance. Statistically significant associations were found between job-strain and working in the private sector $(p=0.037)$, between the Effort-Reward imbalance and a number of surgeries $>5 /$ day $(\mathrm{p}=0.024)$ on the one hand and exposure to violence $(p=0.038)$ on the other.

Conclusion A preventive strategy based on an improvement of working conditions must be implemented against the risk factors of stress in the operating room. 